\title{
Intestinal strongyloidiasis as a presenting symptom of HTLV-1-associated adult T-cell leukemia/lymphoma
}

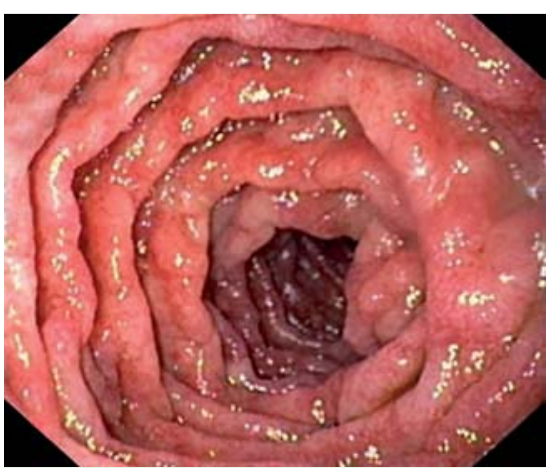

Fig. 1 Gastroduodenoscopy showing thickened folds and erythematous mucosa in the duodenum.

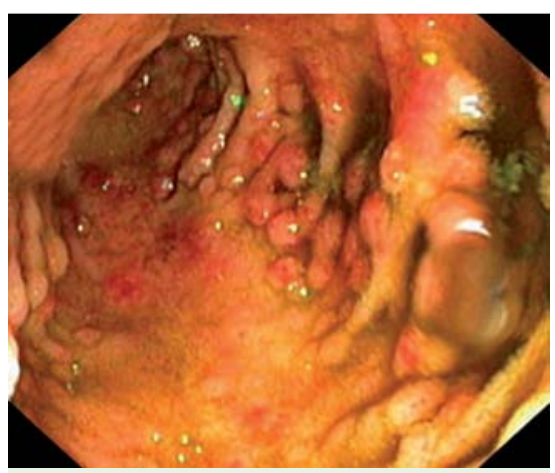

Fig. 2 Colitis with oedema, erosions, and loss of vascular pattern.

A 57-year-old man with diabetes presented with dysphagia, severe weight loss, and frequent watery stools. He had emigrated to the Netherlands from Suriname 23 years ago. Apart from a cachectic appearance, the physical examination revealed no abnormalities. Laboratory investigations showed leukocytosis but no eosinophilia, slightly raised lactate dehydrogenase, and mild hypercalcemia. Gastroduodenoscopy revealed pangastritis and duodenitis ( Fig. 1). Ileocolonoscopy showed a mild, discontinuous colitis, more severe in the proximal colon, and a terminal ileitis ( $\bullet$ Fig. 2). Computed tomography (CT) scanning of the neck, chest, and abdomen showed no lymphadenopathy or splenomegaly. Magnetic resonance imaging (MRI) of the small bowel revealed thickening of the duodenal wall and folds ( Fig. 3). Stool examinations as well as duodenal biopsy samples were positive

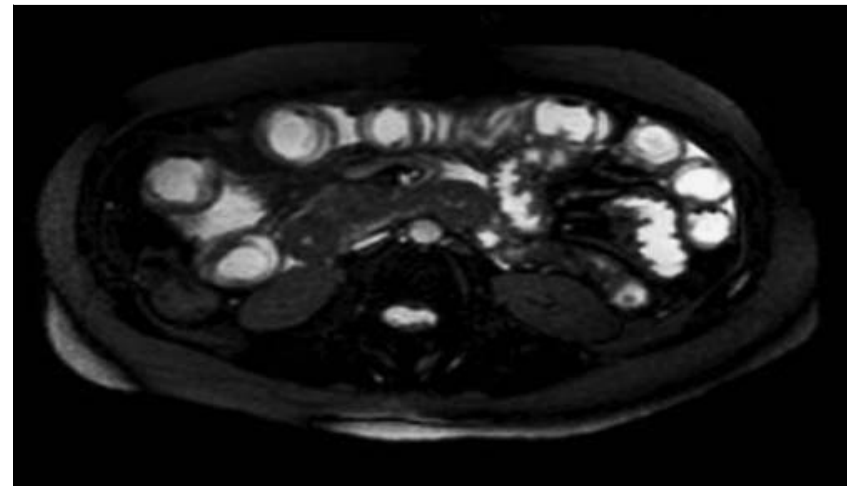

Fig. 3 Magnetic resonance imaging (MRI) of the small bowel, revealing thickening of the duodenal wall and folds.

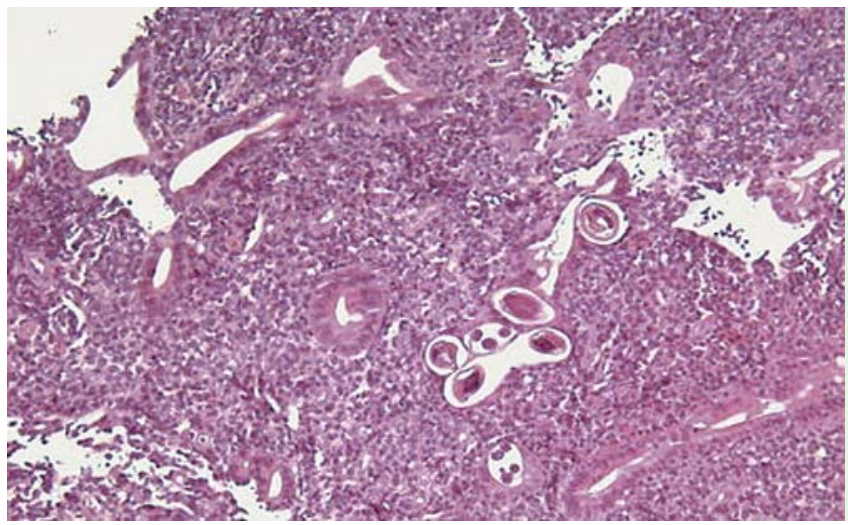

Fig. 4 Duodenal biopsy illustrating microorganisms compatible with S. stercoralis.

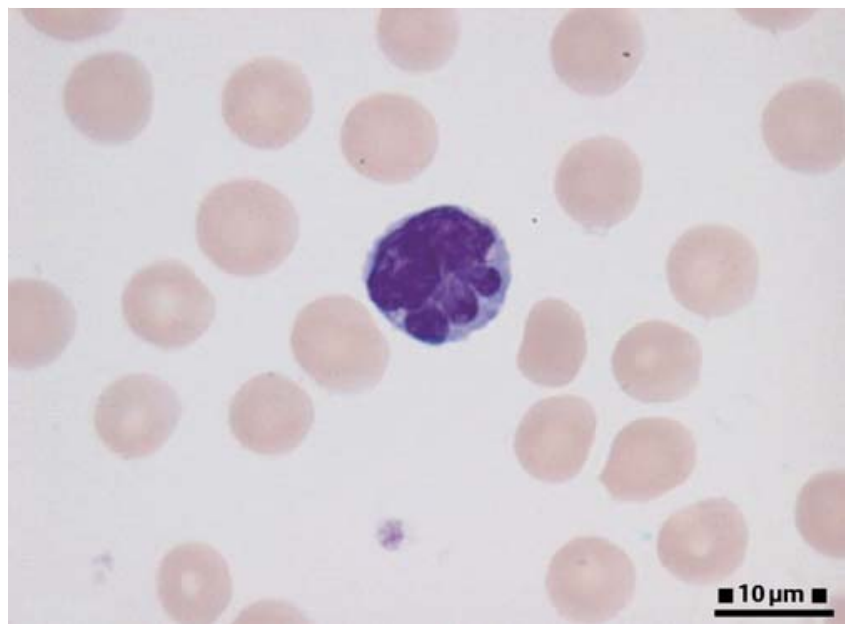

Fig. 5 Multilobulated nuclei or "flower cells" in a peripheral blood smear - characteristic for adult T-cell leukemia/lymphoma. for Strongyloides stercoralis ( $\bullet$ Fig. 4), and treatment with oral ivermectin was initiated. Meanwhile, the hypercalcemia worsened, which was suggestive of human Tcell lymphotropic virus type 1 (HTLV-1)associated adult T-cell leukemia/lymphoma (ATLL). Serological testing for HTLV-1 was positive, and a peripheral blood smear showed the characteristic "flower cells" of ATLL ( $\bullet$ Fig. 5). Bone marrow biopsy and subsequent immunophenotyping were compatible with this diagnosis. The patient was treated with chemotherapy and ritonavir, but died shortly afterwards as a result of Streptococcus milleri sepsis and multiple organ failure. 
S. stercoralis is an intestinal nematode endemic in the (sub)tropical regions of the world [1]. The majority of infections are asymptomatic. However, patients with HTLV-1 coinfection have defective cellmediated immunity and are prone to develop disseminated strongyloidiasis [2]. Among those who contract HTLV-1 infection early in life, a minority may develop ATLL [3].

ATLL is an aggressive lymphoproliferative disease of $\mathrm{CD}^{+}$cells into which the HTLV-1 provirus has integrated. Treatment options are limited and results are disappointing [4]. In conclusion, infection with S. stercoralis should be considered in patients presenting with enterocolitis, especially in those from endemic areas or in those who are immunocompromised [5]. The combination of disseminated strongyloidiasis and hypercalcemia is strongly suggestive of HTLV-1-associated lymphoma.

Endoscopy_UCTN_Code_CCL_1AD_2AZ
M.Grijsen ${ }^{1}$, G.van den Berk ${ }^{1}$, E.Hoekstra $^{2}$, W.Terpstra ${ }^{1}$, S.Veldman ${ }^{2}$, J.Jansen ${ }^{2}$

1 Department of Internal Medicine, Onze Lieve Vrouwe Hospital, Amsterdam, the Netherlands

2 Department of Gastro-enterology, Onze Lieve Vrouwe Hospital, Amsterdam, the Netherlands

\section{References}

1 Chen JJ, Lee CM, Changchan CS. Duodenal Strongyloides stercoralis infection. Endoscopy 1994; 26: 272

2 Verdonck K, Gonzáles E, Van Dooren S et al. Human T-lymphotropic virus 1: recent knowledge about an ancient infection. Lancet Infect Dis 2007; 7: 266 - 281

3 Carvalho EM, Da Fonseca Porto A. Epidemiological and clinical interaction between HTLV-1 and Strongyloides stercoralis. Parasite Immunol 2004; 26: 487 - 497

4 Mahieux R, Gessain A. Adult T-cell leukemia/ lymphoma and HTLV-1. Curr Hematol Malig Rep 2007; 2: 257-264

5 Gorman SR, Craven DE. Strongyloides stercoralis hyperinfection. N Engl J Med 2008; 359: e12
Bibliography

DOI 10.1055/s-0029-1215068

Endoscopy 2009; 41: E271 -E272

(c) Georg Thieme Verlag KG Stuttgart · New York · ISSN 0013-726X

Corresponding author Dr. J. Jansen

Onze Lieve Vrouwe Hospital

Department of Gastro-enterology

PO Box 95500

1090 HM Amsterdam

The Netherlands

Fax: +31-20-5993823

J.M.Jansen@olvg.nl 